\title{
Gastroprotective effect of ghrelin against indomethacin-induced gastric injury in rats: possible role of heme oxygenase-1 pathway
}

\author{
Mona M. Allam and Ola A. El-Gohary \\ Department of Physiology, Faculty of Medicine, Benha University, Benha, Egypt
}

\begin{abstract}
Ghrelin has been shown to ameliorate gastric injury by several mechanisms in experimental animal models. The present study aimed to investigate the effect of pretreatment with ghrelin on indomethacin-induced gastric injury in rats and the role of heme oxygenase-1(HO-1) pathway as a novel mechanism underlying the gastroprotective effect of ghrelin. In all groups studied, ulcer score (U.S), ulcer index (U.I) and preventive index (P.I) were evaluated and the gastric inflammatory biomarkers including levels of tumor necrosis factor- $\alpha$ (TNF- $\alpha$ ), interleukin-1 $\beta$ (IL-1 $\beta$ ) and myeloperoxidase (MPO) activity as well as prostaglandin E2 (PGE2), malondialdehyde (MDA), glutathione (GSH), superoxide dismutase (SOD), HO-1 and bilirubin as an indicator of heme oxygenase activity were measured. Indomethacin induced significant elevation in U.S and U.I as well as the inflammatory and the oxidative markers and reduced the PGE2 in addition to HO-1 level and activity. Pretreatment with ghrelin reversed these results. In order to elucidate the possible role of $\mathrm{HO}-1$ in mediating the protective effects of ghrelin, tin protoporphyrin (SnPP) HO-1 blocker was administrated; it significantly attenuated the gastroprotective effect of ghrelin. In conclusion HO-1 activity significantly contributes toward ghrelin-mediated gastroprotection.
\end{abstract}

Key words: Ghrelin — NSAIDs - Indomethacin — Gastric injury - Heme oxygenase-1

\begin{abstract}
Abbreviations: CO, carbon monoxide; COX, cyclooxygenase; GHS-R, growth hormone secretagogue receptor; GSH, glutathione peroxidase; HO, heme oxygenase; IL-1 $\beta$, interleukin $1 \beta$; IND, indomethacin; MDA, malondialdehyde; MPO, myeloperoxidase; NO, nitric oxide; NSAIDs, nonsteroidal anti-inflammatory drugs; PG, prostaglandin; PGE2, prostaglandin E2; P.I, preventive index; PMN, polymorphonuclear; ROS, reactive oxygen species; SnPP, Tin-protoporphyrin; SOD, superoxide dismutase; TNF- $\alpha$, tumor necrosis factor- $\alpha$; U.I, ulcer index; U.S, ulcer score.
\end{abstract}

\section{Introduction}

Gastric ulcers associated with the utilization of nonsteroidal anti-inflammatory drugs (NSAIDs) remain one of the major clinical problems all over the world (Dhiyaaldeen et al. 2014). The frequency of usage is attributed to the fact that NSAIDs-induced gastric ulcers are the second most common etiology of gastric ulcers (Adinortey et al. 2013). The pathophysiology of gastric ulcer has generally focused on an imbalance between aggressive and defensive factors of the gastric mucosa (Tulassay and Herszényi 2010). Indometha-

Correspondence to: Mona M. Allam, Department of Physiology, Faculty of Medicine, Benha University, Benha, Egypt

E-mail: monamaher8011@yahoo.com cin (IND), a representative of NSAIDs family, is known to produce serious side effects in the mucosa of the stomach such as erosions, and ulcerative lesions (Prasad et al. 2012): It was reported that oral administration of IND in rats is well known to cause ulcerative lesions in the gastric mucosa (Kim et al. 2011). Several mechanisms underlie the effect of IND including inhibition of prostaglandin synthesis and generation of reactive oxygen species (ROS) (Takeuchi et al. 2011).

Ghrelin is a 28 -amino acid peptide that exerts several biological activities including regulation of food intake and energy balance (Harrison et al. 2008). Ghrelin has been discovered in the gastrointestinal tract, particularly in gastric mucosa, as an endogenous ligand for growth hormone secretagogue receptor (GHS-R) (Kojima and Kangawa 2005). Specifically, the majority of plasma ghrelin originates in the 
oxyntic gland where A-like cells exist (Gaytan et al. 2003), it was proposed that nitric oxide (NO) pathway, antioxidant and anti-inflammatory effects may underlie the gastroprotective effect of ghrelin (Sibilia et al. 2003; Gamal El-Din et al. 2012). However, other underlying protective mechanisms of ghrelin in gastric injury remain to be investigated.

Heme oxygenase $(\mathrm{HO})$ is the rate-limiting enzyme in the oxidation of heme to carbon monoxide (CO) and biliverdin, which is changed over into bilirubin (Wagener et al. 1999). $\mathrm{HO}-1$, an inducible isoform is produced under stressful states such as hypoxia (Ryter et al. 2002), free radicals and chemical stressor (Shibahara 2003). Induction of the important cytoprotective molecule HO-1 has been shown to have vasodilatory, and anti-inflammatory effects (Wagener et al. 2001).

HO-1 is expressed in gastric epithelium and previous works have shown increased HO-1 expression in an inflamed stomach (Barton et al. 2003) and during the healing of gastric ulcers (Guo et al. 2003). HO-1 and its metabolites have the potential to counteract the NSAIDs-induced gastric injury by different mechanisms, including antioxidant properties and their ability to restore mucosal blood flow (Uc et al. 2012). Previous studies had demonstrated an inducible effect of ghrelin on HO-1 that provides efficient cytoprotection in ischemia-reperfusion liver injury secondary to transplantation or hemorrhage resuscitation in rats (Bauer and Bauer 2002) and in case of paracetamolinduced acute liver injury rat model (Ahmed et al. 2014), also it was reported that the neuroprotective effects of ghrelin may be mediated by the up-regulation of gene expression of $\mathrm{HO}-1$ (Jazwa and Cuadrado 2010). The present study was designed to investigate whether HO-1 dependent pathway would be one of the mechanisms underlying the gastroprotective effect of ghrelin against NSAIDs-induced gastric injury in rats.

\section{Material and Methods}

\section{Drugs and chemicals}

Ghrelin was obtained from Sigma (St. Louis, MO, USA) as powder, it was dissolved in saline. IND was obtained from Kahira Pharm \& Chem. Ind. Co. (Egypt) as powder, it was suspended in carboxymethylcellulose 1\% (El-Nasr pharmaceutical \& Chemical Co, Egypt). Tin protoporphyrin (SnPP) was obtained from (Tocris Bioscience, UK) and was prepared in $0.1 \mathrm{~mol} / 1 \mathrm{NaOH}$ and phosphate-buffered saline, $\mathrm{pH}$ was adjusted to $\mathrm{pH}$ 7.4. All drugs solutions and suspensions were freshly prepared. All other chemicals were of analytical grade and obtained from standard commercial suppliers.

\section{Animals}

This study was conducted on 40 adult Wistar albino male rats, 6-8 weeks old, animals were purchased from Abou-Rawash
Animal House (Giza, Egypt), weighing $200 \pm 20$ g. Rats were housed at room temperature in metal cages with a 12:12-h light/dark cycle, four rats in each cage. The present study was carried out in accordance with the guidelines set by the Research Ethics Committee of Benha Faculty of Medicine.

\section{Experimental design}

The rats were fasted for $24 \mathrm{~h}$ prior to the experiment in mesh bottomed cages to minimize corporophagia. The animals had free access to water except for the last hour before the experiment. All experiments were performed during the same time of the day to avoid variations due to diurnal rhythms of putative regulators of gastric functions (Bregonzio et al. 2003). The rats were randomly assigned into five groups (eight rats in each group):

Group I: control group; rats were injected with saline subcutaneously (s.c.) as a vehicle.

Group II: rats were injected with ghrelin $(40 \mu \mathrm{g} / \mathrm{kg}$; s.c. $)$ (Khalefa et al. 2010).

Group III: IND was administered orally via gavage at a single dose (30 mg/kg) (Bhargava et al. 1973) to induce the gastric ulcer in rats.

Group IV: rats were pretreated with ghrelin $(40 \mu \mathrm{g} / \mathrm{kg}$; s.c), 30 min before induction of gastric ulceration by IND.

Group V: rats were pretreated with a potent inhibitor of HO-1 activity, tin-protoporphyrin (SnPP) $30 \mathrm{mg} / \mathrm{kg}$; intravenously under light ether anesthesia, $10 \mathrm{~min}$ before administration of ghrelin, which was followed by IND (Yoda et al. 2010).

\section{Assessment of gastric mucosal lesions}

Twenty four hours later after administration of IND during which they were fasting (Yoda et al. 2010), rats of all groups were anaesthetized with urethane $(1.5 \mathrm{~g} / \mathrm{kg}$; i.p.) before cervical dislocation, stomachs were rapidly removed, opened by an incision along the greater curvature and washed by cold saline solution to remove the gastric content remnants and blood clots. The stomachs were stretched and pinned out flat on a cork board and photographed, the number and the severity of discrete areas of damage in the mucosa were inspected using a magnifier and scored by trained independent observer who was unaware of the drug treatment, the ulcer score (U.S) was determined according to the method described by Dekanski et al. (1975) as follows: 0, no damage; 1, blood at the lumen; 2, pinpoint erosions; 3 , one to five small erosions $<2 \mathrm{~mm}$; 4 , more than five small erosions $<2 \mathrm{~mm}$; , one to three large erosions $>2 \mathrm{~mm} ; 6$, more than three large erosions $>2 \mathrm{~mm}$. The ulcer index (U.I) was calculated by the following equation: U.I. = mean ulcer score of similarly treated group $\times$ percentage of ulcerated animals of the same group and the preventive index (P.I) was calculated by the equation (Hano et al. 1976): 


$$
P . I=\frac{(\text { U.I of IND group }- \text { U.I of pretreated group }}{\text { U.I of IND group })} \times 100
$$

\section{Biochemical analysis of gastric mucosa}

Sample of the stomach of each rat was immersed in IND $(10 \mu \mathrm{g} / \mathrm{ml})$ for $20 \mathrm{~min}$ to inhibit further formation and release of PGs, then stored at $-80^{\circ} \mathrm{C}$. Subsequently, the gastric mucosa was scraped, homogenized in $2 \mathrm{ml}$ normal saline containing $0.1 \mathrm{M}$ dithiothreitol and centrifuged at $2000 \mathrm{rpm}$ for $10 \mathrm{~min}$ at room temperature. The supernatant was used for determination of prostaglandin E2 (PGE2). PGE2 in the gastric mucosa was determined by enzyme-linked immunosorbent assay (ELISA) using PGE2 assay kit (R\&D Systems, USA), and based on the competitive binding technique in which PGE2 present in a sample competes with a fixed amount of horseradish peroxidase (HRP)-labeled PGE2 for sites on a monoclonal antibody (Brzozowski et al. 2007).

The mucosa of another part of the stomach was also scrapped, homogenized in cold phosphate buffer $(0.05 \mathrm{M}$, $\mathrm{pH}$ 7.4) and centrifuged at $2000 \mathrm{rpm}$ for $10 \mathrm{~min}$; the supernatant was then kept at $-80^{\circ} \mathrm{C}$ for measurement of (i) malondialdehyde (MDA) content in the gastric mucosa as an indicator of lipid peroxidation, (ii) the levels of proinflammatory cytokines; tumor necrosis factor (TNF- $\alpha$ ) and interleukin $1 \beta$ (IL-1 $\beta$ ), and (iii) hemeoxygenase-1 (HO-1) level.

MDA levels in the gastric mucosa were determined as an indicator of lipid peroxidation by thiobarbituric acid method (Cayman Chemical Co., Ann Arbor, MI, USA) (Okhawa et al. 1979), the glutathione (GSH) activity (Sedlak et al. 1968) and superoxide dismutase (SOD) activity using Cayman assays (Cayman Chemical Co., Ann Arbor, MI, USA) activity as antioxidants (Das et al. 2000). The levels of pro-inflammatory cytokines TNF- $\alpha$ and IL- $1 \beta$ were determined by using ELISA assay using standard kits (Ray Biotech, Inc., USA) (Cunha et al. 1993), myeloperoxidase (MPO) activity; an index of polymorphonuclear (PMN) cell accumulation into gastric tissue was determined according to Bradley et al. (1982). The glandular stomach was weighed and subsequently homogenized in phosphate buffer. The samples were freeze-thawed 3 times and centrifuged at $15,000 \times g$ for 20 minutes at $4^{\circ} \mathrm{C}$. Finally the change in absorbance at $460 \mathrm{~nm}$ over $3 \mathrm{~min}$ was measured with a spectrophotometer.

Gastric mucosal HO-1 was determined by ELISA using Rat HO-1 immunoassay kit (Biovendor, USA), and based on the competitive binding technique in which $\mathrm{HO}-1$ present in a sample is captured by the immobilized antibody and is detected with an IgG antibody conjugated to horseradish peroxidase (Chen et al. 2003) and bilirubin level as a measure of $\mathrm{HO}$ activity was measured spectrophotometrically using commercial kit from BioMed Diagnostics (White City, OR, USA) (Motterlini et al. 1996).

\section{Histological evaluation of gastric damage}

For histological evaluation, stomach samples were fixed in 10\% formalin solution where they remained for $24 \mathrm{~h}$. After fixation, the samples were transferred to a solution of $70 \%$ alcohol. The material was then embedded in paraffin and sectioned. Sections ( $4 \mu \mathrm{m}$ thick) were deparaffinized, stained with hematoxylin and eosin (H\&E), and then examined under a light microscope by an experienced pathologist who was blinded to the treatment. Gastric microscopic damage was scored on a $0-14$ scale according to the criteria described by Laine and Weinstein (1988). Briefly, a $1 \mathrm{~cm}$ segment of each histological section was examined for epithelial cell loss (score: $0-3$ ), edema in the upper mucosa (score: $0-4$ ), hemorrhagic damage (score: $0-4$ ), and the presence of inflammatory cells (score: $0-3$ ).

\section{Statistical Analysis}

All the data are presented as mean \pm standard deviation (SD). Evaluation of differences between groups was performed using one-way ANOVA with post hoc test (LSD) between groups with SPSS 19.0 software. A value $p<0.05$ was considered statistically significant.

\section{Results}

\section{Effect of ghrelin administration on IND-induced gastric lesions in rats and the role of $\mathrm{HO}-1$}

The present work revealed that IND administration in Group III resulted in a marked ulcerative lesion, it was accompanied by a significant $(p<0.05)$ elevation in the levels of U.S and U.I as compared with that of control rats. Pretreatment with ghrelin in Group IV significantly $(p<0.05)$ reduced the U.S and U.I showing P.I of $77.1 \%$ as compared to Group III. On the other hand, the HO-1 blocker (SnPP) pretreatment (Group V) abolished the protective effect of ghrelin in rats subjected to gastric lesions as it significantly $(p<0.05)$ increased the U.S and U.I with P.I of $32.98 \%$ as compared to ghrelin-pretreated group (Group IV) (Table 1 and Fig. 1).

Effect of ghrelin administration on inflammatory changes that associate with the IND-induced gastric lesions in rats and the role of $\mathrm{HO}-1$

Quantification data for the levels of the pro-inflammatory cytokines (TNF- $\alpha$ and IL-1 $\beta$ ) in the IND-treated rats (Group III) showed a significant $(p<0.05)$ elevation compared to control rats. However, these cytokines showed a significant $(p<0.05)$ reduction in rats pretreated with ghrelin (Group IV) compared to the IND-treated rats group (Group III). Furthermore, the pretreatment with 

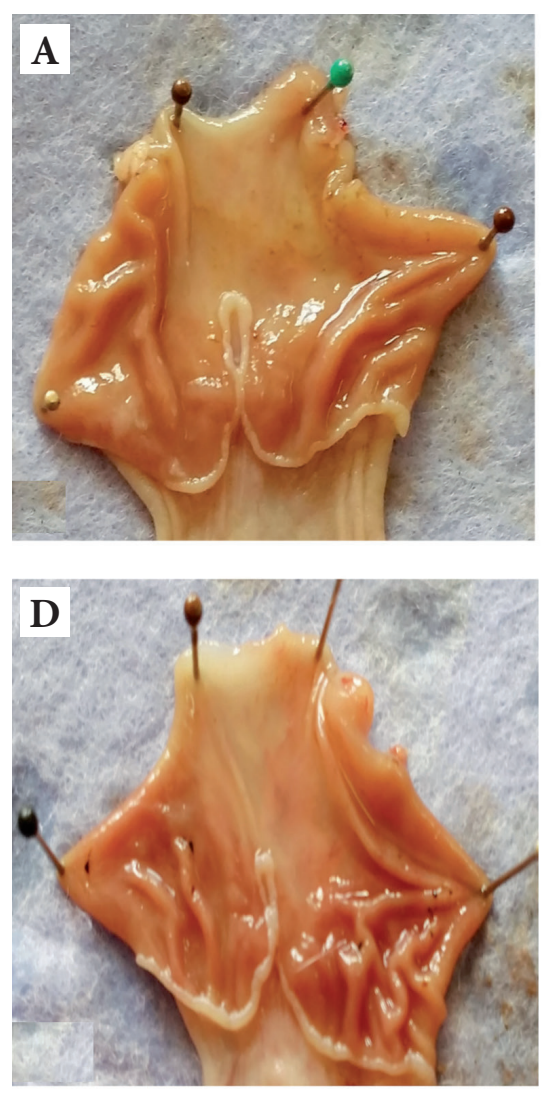
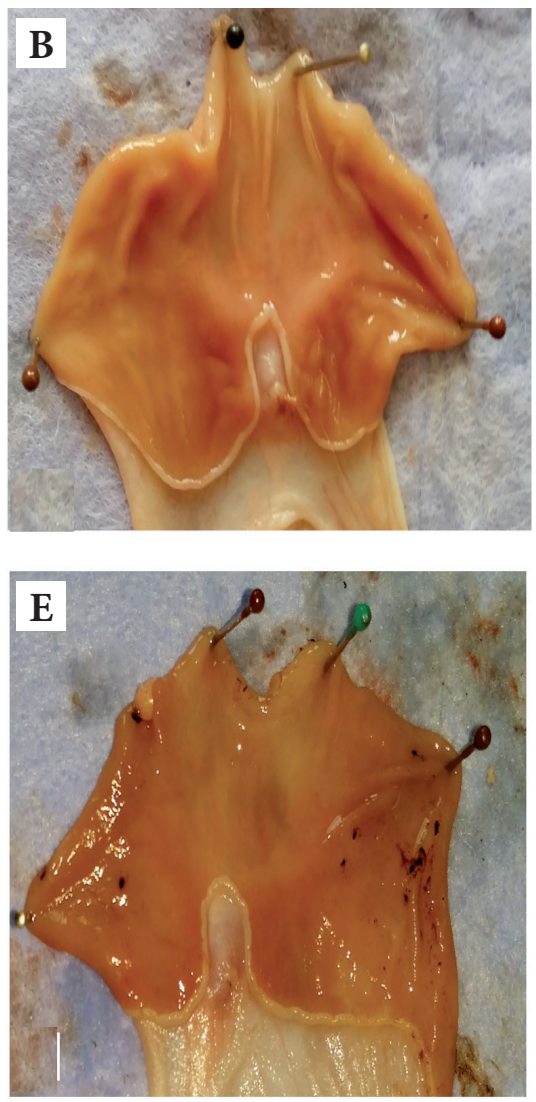

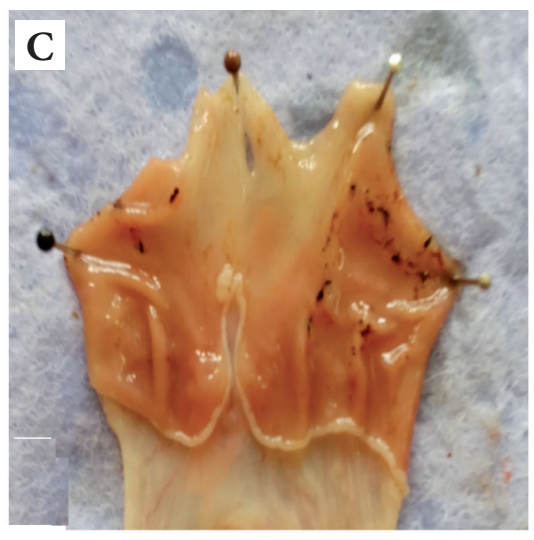

Figure 1. Photomicrographs showing macroscopic appearance of the gastric mucosa in Group I (control group, injected with saline as a vehicle; $\mathbf{A}$ ), Group II (injected with ghrelin (40 $\mu \mathrm{g} / \mathrm{kg}$; s.c.; B), Group III (indomethacin was administered orally at a single dose $30 \mathrm{mg} / \mathrm{kg}$; C), Group IV (ghrelin was given at $40 \mu \mathrm{g} / \mathrm{kg}$; s.c. $30 \mathrm{~min}$. before induction of gastric ulceration by indomethacin; D), Group V (SnPP HO-1 blocker was given at $30 \mathrm{mg} / \mathrm{kg}$; i.v. $10 \mathrm{~min}$. before administration of ghrelin, which was followed by indomethacin; E). the HO-1 blocker (SnPP) (Group V) abolished the effect of ghrelin pretreatment as it resulted in a significant $(p<0.05)$ increase of TNF- $\alpha$ and IL-1 $\beta$ as compared to Group IV (Table 2).

Similarly the MPO activity in IND-treated group (Group III) showed a significant $(p<0.05)$ elevation compared to the control group (Group I), however, pretreatment with ghrelin as in Group IV resulted in its decrease significantly $(p<0.05)$ as compared to Group III. On the other hand, the pretreatment with the $\mathrm{HO}-1$ blocker (SnPP)
(Group V) abolished the effect of ghrelin pretreatment as it resulted in a significant $(p<0.05)$ increase of MPO activity as compared to Group IV (Table 2).

The PGE2 levels were significantly $(p<0.05)$ reduced in the IND-treated group (Group III) compared to the control group, however, pretreated rats with ghrelin (Group IV) showed a significant $(p<0.05)$ elevation as compared to Group III. HO-1 blocker (SnPP) pretreatment (Group V) resulted in its significant $(p<0.05)$ decrease as compared to Group IV (Table 2).

Table 1. Changes in ulcer score (severity), percentage of ulceration, ulcer index, preventive index and microscopic damage scores in control and differently treated groups

\begin{tabular}{lccccc}
\hline & \multicolumn{5}{c}{ Group } \\
\cline { 2 - 6 } & I & II & III & IV & V \\
\hline Ulcer score & 0 & 0 & $4.82 \pm 0.11^{\mathrm{a}}$ & $1.47 \pm 0.23^{\mathrm{a}, \mathrm{b}}$ & $3.23 \pm 0.30^{\mathrm{a}, \mathrm{b}, \mathrm{c}}$ \\
\% of ulceration & 0 & 0 & $100 \%$ & $75 \%$ & $100 \%$ \\
Ulcer index & 0 & 0 & $482^{\mathrm{a}}$ & $110.25^{\mathrm{a}, \mathrm{b}}$ & $323^{\mathrm{a}, \mathrm{b}, \mathrm{c}}$ \\
Preventive index & - & - & - & $77.1 \%$ & $32.98 \%$ \\
Microscopic score & $0.6 \pm 0.29$ & $0.3 \pm 0.12$ & $11.9 \pm 0.67^{\mathrm{a}}$ & $6.2 \pm 0.70^{\mathrm{a}, \mathrm{b}}$ & $8.3 \pm 3.49^{\mathrm{a}, \mathrm{b}, \mathrm{c}}$ \\
\hline
\end{tabular}

Data are represented as mean $\pm \mathrm{SD}, n=8 .{ }^{\mathrm{a}} p<0.05$ significant difference compared with control group; ${ }^{\mathrm{b}} p<0.05$ significant difference compared with Group III; ${ }^{c} p<0.05$ significant difference compared with Group IV. (For more information, see section Materials and Methods). 
Table 2. Changes in pro-inflammatory cytokines (TNF- $\alpha$, IL-1 $\beta$ ), myeloperoxidase (MPO) activity and prostaglandin E2 (PGE2) in gastric mucosa of control and differently treated groups

\begin{tabular}{lrrrrr}
\hline & \multicolumn{5}{c}{ Group } \\
\cline { 2 - 6 } & \multicolumn{1}{c}{ I } & \multicolumn{1}{c}{ II } & III & IV & V \\
\hline TNF- $\alpha$ (pg/g) & $1239.1 \pm 35.6$ & $1215.7 \pm 59.1$ & $2518.7 \pm 48.6^{\mathrm{a}}$ & $1427.6 \pm 73.1^{\mathrm{a}, \mathrm{b}}$ & $2096.2 \pm 73.4^{\mathrm{a}, \mathrm{b}, \mathrm{c}}$ \\
IL-1 $\beta$ (pg/g) & $538.7 \pm 15.5$ & $536.4 \pm 17.7$ & $928.9 \pm 24.6^{\mathrm{a}}$ & $628.5 \pm 16.6^{\mathrm{a}, \mathrm{b}}$ & $827.8 \pm 20.8^{\mathrm{a}, \mathrm{b}, \mathrm{c}}$ \\
MPO (U/g) & $9.6 \pm 0.48$ & $9.3 \pm 0.42$ & $25.4 \pm 2.9^{\mathrm{a}}$ & $14.9 \pm 1.4^{\mathrm{a}, \mathrm{b}}$ & $20.1 \pm 0.71^{\mathrm{a}, \mathrm{b}, \mathrm{c}}$ \\
PGE2 (ng/g) & $538.0 \pm 24.9$ & $552.3 \pm 13.0$ & $256.6 \pm 30.5^{\mathrm{a}}$ & $454.4 \pm 24.1^{\mathrm{a}, \mathrm{b}}$ & $364.7 \pm 8.5^{\mathrm{a}, \mathrm{b}, \mathrm{c}}$ \\
\hline
\end{tabular}

Data are represented as mean $\pm \mathrm{SD}, n=8 .{ }^{\mathrm{a}} p<0.05$ significant difference compared with Group I; ${ }^{\mathrm{b}} p<0.05$ significant difference compared with Group III; ${ }^{c} p<0.05$ significant difference compared with Group IV. TNF- $\alpha$, tumor necrosis factor $\alpha$; IL- $1 \beta$, interleukin $1 \beta$. (For more information, see section Materials and Methods).

Effect of ghrelin administration on oxidative stress changes that associate with the IND-induced gastric lesions in rats and the role of $\mathrm{HO}-1$

The gastric injury induced by the IND (Group III) increased gastric MDA significantly $(p<0.05)$ with a parallel significant $(p<0.05)$ decrease in SOD and GSH content as compared to control rats. Pretreatment with ghrelin (Group IV) resulted in a significant $(p<0.05)$ decrease in MDA and a significant $(p<0.05)$ increase in GSH and SOD content as compared to Group III. Similar to other parameters, the HO-1 blocker (SnPP) pretreatment (Group V) abolished the protective effect of ghrelin as it resulted in a significant $(p<0.05)$ increase regard MDA and a significant $(p<0.05)$ decrease regard GSH and SOD as compared to Group IV (Table 3).

\section{Effect of ghrelin administration on HO-1 and bilirubin gastric levels}

From our data, we observed that IND administration (Group III) reduced gastric HO-1 level significantly ( $p<$ $0.05)$ as compared to control group. Pretreatment with ghrelin (Group IV) significantly $(p<0.05)$ increased the HO-1 level as compared to Group III, however, the pretreatment with the HO-1 blocker (SnPP) (Group V) resulted in non-significant change in the level of the gastric $\mathrm{HO}-1$ as compared to Group IV (Table 4).

The gastric injury induced by the IND (Group III) reduced the gastric bilirubin significantly $(p<0.05)$ as compared to the control group, however, ghrelin pretreatment (Group IV) significantly $(p<0.05)$ increased the bilirubin level as compared to Group III. Pretreatment with the HO-1 blocker (SnPP) (Group V) significantly $(p<0.05)$ reduced the bilirubin level compared with ghrelin-treated group (Group IV) (Table 4).

\section{Histopathological results}

Histopathological results show that stomach of rats from control and ghrelin groups (Fig. 2A and B, respectively), by microscopic examination, revealed features of normal intact mucosa with normal mucosal thickness and perpendicular alignment of the fundic glands with microscopic scores $0.6 \pm 0.29$ and $0.3 \pm 0.12$, respectively (Table 1). On the other hand, the stomach of rats treated with IND (Group III) showed sever epithelial cell loss, sever edema, marked congestion of blood vessels, necrosis, moderate hemorrhage and marked inflammatory cells infiltration (Fig. 2C and D) with a microscopic score $11.9 \pm 0.67$ (Table 1). The microscopic examination of stomach from rats pretreated with ghrelin (Group IV) (Fig. 2E) revealed mild epithelial cell loss with maintenance of basal epithelium,

Table 3. Changes in oxidative stress markers, lipid peroxidation (MDA) and antioxidants (GSH, SOD) in gastric mucosa of control and differently treated groups

\begin{tabular}{lcccrr}
\hline & \multicolumn{5}{c}{ Group } \\
\cline { 2 - 6 } & \multicolumn{1}{c}{ I } & II & III & IV & V \\
\hline MDA $(\mathrm{nmol} / / \mathrm{g})$ & $4.6 \pm 0.2$ & $4.5 \pm 0.2$ & $15.4 \pm 0.4^{\mathrm{a}}$ & $8.3 \pm 0.3^{\mathrm{a}, \mathrm{b}}$ & $13.5 \pm 0.5^{\mathrm{a}, \mathrm{b}, \mathrm{c}}$ \\
GSH $(\mu \mathrm{mol} / \mathrm{g})$ & $1.4 \pm 0.1$ & $1.4 \pm 0.2$ & $0.66 \pm 0.1^{\mathrm{a}}$ & $1.1 \pm 0.1^{\mathrm{a}, \mathrm{b}}$ & $0.8 \pm 0.05^{\mathrm{a}, \mathrm{c}}$ \\
SOD $(\mu / \mathrm{g})$ & $340.5 \pm 21.0$ & $351.9 \pm 16.5$ & $229.3 \pm 17.3^{\mathrm{a}}$ & $277.2 \pm 8.5^{\mathrm{a}, \mathrm{b}}$ & $246.7 \pm 10.5^{\mathrm{a}, \mathrm{b}, \mathrm{c}}$ \\
\hline
\end{tabular}

Data are represented as mean $\pm \mathrm{SD}, n=8 .{ }^{\mathrm{a}} p<0.05$ significant difference compared with Group I; ${ }^{\mathrm{b}} p<0.05$ significant difference compared with Group III; ${ }^{c} p<0.05$ significant difference compared with Group IV. MDA, malondialdehyde; GSH, glutathione peroxidase; SOD, superoxide dismutase. (For more information, see section Materials and Methods). 
mild congestion and edema with moderate inflammatory cells infiltration which all confirms the gross findings of protection of the mucosa with ghrelin (Fig. 1D) with a microscopic score $6.2 \pm 0.70$ (Table 1), sever epithelial loss, moderate congestion, edema and moderate inflammatory cells infiltration with a microscopic score $8.3 \pm 3.49$ which also confirms the reduction of the protective effect of ghrelin was observed with the use of HO-1 blocker (SnPP) in Group V (Fig. 2F).

\section{Discussion}

The diversity of etiological factors underlying gastric ulcers and the complex nature of pathways participating in its treatment always make peptic ulcers prevention and treatment a complicated challenge. Keeping the balance between the aggressive and protective factors of the gastric mucosa is a critical objective in peptic ulcer management (El-Moselhy et al. 2009). The present study was designed to investigate the role of the HO-1 pathway in the gastroprotective effect of ghrelin against NSAIDs-induced gastric injury in rats, exploring these underlying mechanisms might provide some useful information for treatment of the gastric injury.

The results of the present study showed that administration of IND at a single dose ( $30 \mathrm{mg} / \mathrm{kg}$; p.o.) caused multiple mucosal injuries by gross examination along with significant increase in gastric U.I as compared with control rats. This result was in agreement with previous studies (Heeba et al. 2009; Kim et al. 2011) that reported an increase in U.S and U.I in IND-treated rats. Moreover, these results were confirmed by histopathological examination of gastric mucosa in IND-administered rats, as it showed epithelial loss, congested blood vessels with inflammatory cells infiltration. IND-induced mucosal injury is attributed to various processes, including infiltration of leukocytes, inhibition of PGE2, initiation of lipid peroxidation, decreasing the levels of antioxidants, and induction of apoptosis (Sabina et al. 2007).

In the present study, IND significantly elevated gastric TNF- $\alpha$ and IL- $1 \beta$ levels along with increased MPO activity that is considered an index of PMN cells accumulation into gastric tissue as compared to control group. These results are in accordance with the work of other investigators (Sabina et al. 2007; Aliye et al. 2012). PMN migration is an early and critical event in the pathogenesis of gastric mucosal injury caused by IND. TNF- $\alpha$ causes PMN migration through upregulating the expression of adhesion molecules in both neutrophil and endothelial cells (de Souza et al. 2011).

PG, a key molecule that has a gastroprotective effect and stimulates the ulcer healing mechanism, is synthesized in the mucosal cells by cyclooxygenase (COX) enzymes. It stimulates the secretion of bicarbonates and mucus, maintains mucosal blood flow, regulates mucosal turnover, and induces angiogenesis (Adhikary et al. 2011). Our experimental results were in line with previous data (Brzozowski et al. 2005), that showed that exposure to IND significantly reduced gastric mucosal PGE2 level. This result might be explained by the inhibition of COX activity and by the conversion of PGs into products of oxidation such as 8-iso-PGF2 alpha in the presence of oxidative damage (Natale et al. 2004). In addition, oxidative stress could inhibit COX activity, thus reducing PG levels (Fujimoto et al. 2004).

Experimental studies have shown that ROS play certain roles in IND-induced gastric mucosal damage (Suleyman et al. 2009). Agents such as IND initiate lipid peroxidation by functioning as oxidants and cause damage by producing ROS. A number of enzymatic and non-enzymatic defense mechanisms such as SOD and GSH respectively reduce or prevent the oxidative tissue damage of gastric mucosa after administration of NSAIDs (Polat et al. 2011). These enzymes play an important role in the elimination of oxygen free radicals and lipid hydroperoxides in the gastric mucosal cell (Kim et al. 2011). Previous studies demonstrated an increase in MDA with a decrease in antioxidants such as GSH and SOD in gastric mucosa of IND-treated rats (Abdallah et al. 2011; Kim et al. 2011). Consistent with these findings, this work revealed that administration of IND significantly increased the lipid peroxidation (MDA) and decreased the level of non-enzymatic (GSH) and the activity of enzymatic (SOD) antioxidants in the gastric mucosa of an IND-administered rat.

In the present work IND significantly reduced the gastric mucosal HO-1 in spite of considering IND as one of cellular stress inducers. These results are supported by the studies of Song et al. (2008) and Aburaya et al. (2006) who reported that IND did not upregulate $\mathrm{HO}-1$ expression but lead to gastric

Table 4. Changes in heme oxygenase-1 (HO-1) and bilirubin levels in gastric mucosa of control and differently treated groups

\begin{tabular}{lccccc}
\hline & \multicolumn{5}{c}{ Group } \\
\cline { 2 - 6 } & I & II & III & IV & V \\
\hline HO-1 (pg/mg) & $1.7 \pm 0.1$ & $2.4 \pm 0.2^{\mathrm{a}}$ & $1.3 \pm 0.1^{\mathrm{a}}$ & $2.4 \pm 0.1^{\mathrm{a}, \mathrm{b}}$ & $2.3 \pm 0.05^{\mathrm{a}, \mathrm{b}}$ \\
Bilirubin (mg/dl) & $0.07 \pm 0.006$ & $0.3 \pm 0.03^{\mathrm{a}}$ & $0.02 \pm 0.007^{\mathrm{a}}$ & $0.36 \pm 0.03^{\mathrm{a}, \mathrm{b}}$ & $0.04 \pm 0.01^{\mathrm{a}, \mathrm{b}, \mathrm{c}}$ \\
\hline
\end{tabular}

Data are represented as mean $\pm \mathrm{SD}, n=8 .{ }^{\mathrm{a}} p<0.05$ significant difference compared with Group I; ${ }^{\mathrm{b}} p<0.05$ significant difference compared with Group III; ${ }^{c} p<0.05$ significant difference compared with Group IV. (For more information, see section Materials and Methods). 
mucosal damage through both necrosis and apoptosis. This reduction was associated with a subsequent decrease in the gastric bilirubin level as an indicator of the HO-1 activity (Huang et al. 2005).

Pretreatment of rats with ghrelin $(40 \mu \mathrm{g} / \mathrm{kg}$; s.c.), before induction of gastric injury, resulted in amelioration of gastric injury. Specifically, it significantly decreased the gastric U.I showing P.I 77.1\% as compared with IND group. These observations were confirmed by histopathological examination that showed a reduction of the depth and severity of IND induced gastric mucosal lesions. These results are in agreement with previously published results (Sibilia et al. 2003; Konturek et al. 2004; Khalefa et al. 2010); it was reported that exogenous ghrelin administration attenuates the experi- mentally induced gastric mucosal lesions and exert certain gastroprotective effect with several possible mechanisms underlying the protective effect of ghrelin.

In contrast to our findings, Suzuki et al. (2006) reported that plasma ghrelin levels were significantly higher in patients with peptic ulcer than in those with gastritis without ulcer, which suggests a possible relationship between mucosal injury susceptibility and the elevated plasma ghrelin.

In order to explain the protective effect of ghrelin on gastric injury induced by IND plasma TNF- $\alpha$ and IL- $1 \beta$, as markers for inflammation, together with gastric PGE2 were measured. We also measured MDA, GSH, and SOD content, as markers for the oxidative stress and the HO-1 gastric level together with bilirubin.
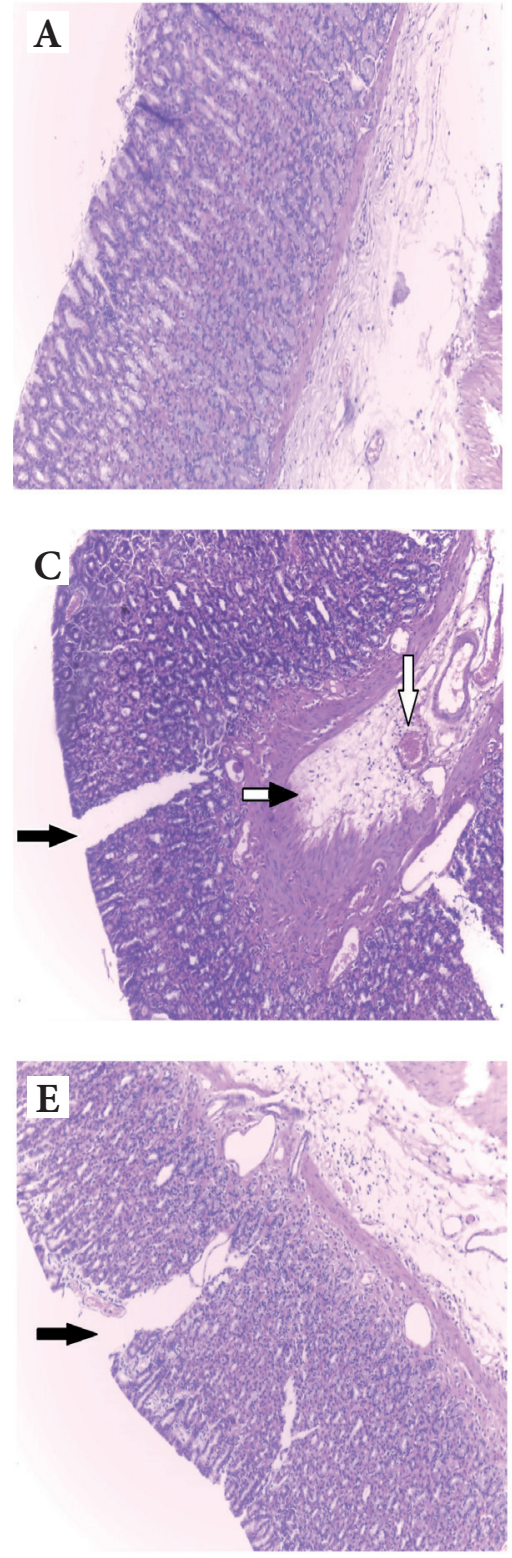
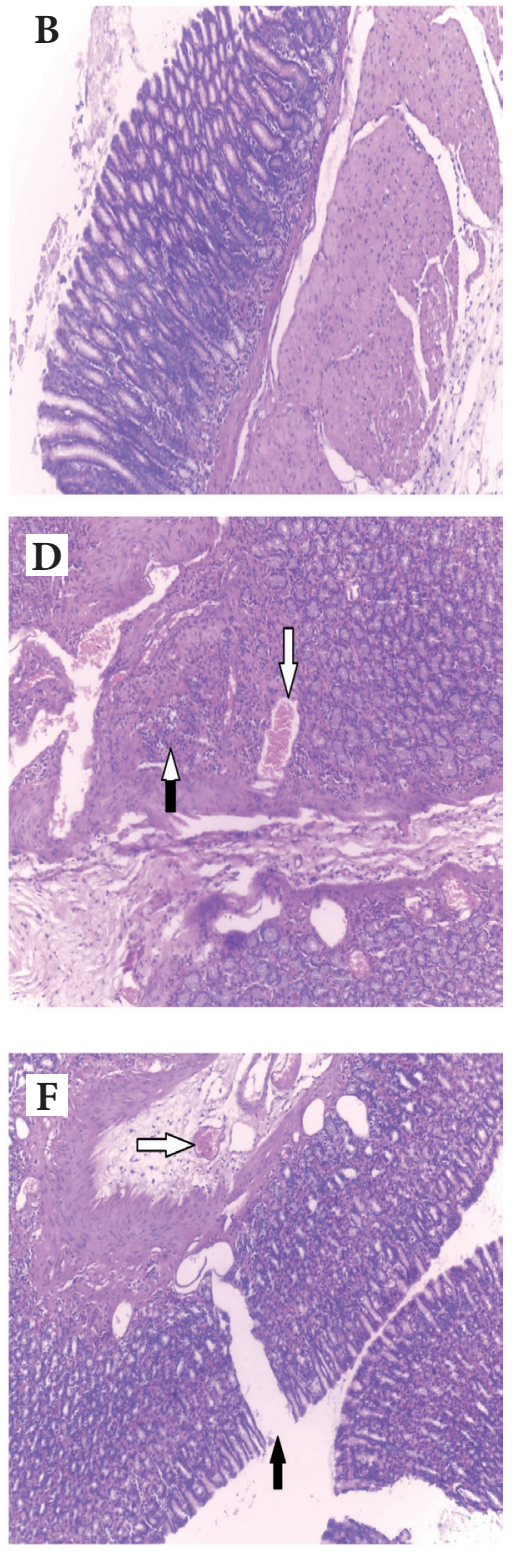

Figure 2. Histological evaluation (H\&E) of the gastric mucosa in Group I (A); Group II (B) showing normal intact mucosa with normal mucosal thickness and perpendicular alignment of the fundic glands; Group III (C, D) showing epithelial cell loss, submucosal edema, congestion of blood vessels and inflammatory cells infiltration (white arrowhead); Group IV (E) showing mild epithelial cell loss with reduction in the severity of gastric mucosal lesions; Group V (F) showing congested blood vessels with epithelial loss. Black arrow; epithelial cell loss; black arrowhead, submucosal edema; white arrow, congestion of blood vessels; white arrowhead, inflammatory cells infiltration. (Magnification $\times 200$ ). (For more information, see section Materials and Methods). 
The reduction of the inflammatory markers including, gastric levels of TNF- $\alpha$ and IL- $1 \beta$ and the MPO activity, suggesting that the gastroprotective effect of ghrelin in part dependent on its inhibitory effect on neutrophil infiltration and the neutrophil-associated TNF- $\alpha$ and IL- $1 \beta$ response. This is in accordance with Konturek et al. (2004), who demonstrated that the treatment with ghrelin caused a dose-dependent decrease in TNF- $\alpha$ mRNA expression indicating an important anti-inflammatory effect of this peptide and Dixit et al. (2004) who reported that ghrelin also is known to exert certain effects on the immune system including inhibition of expression of the pro-inflammatory cytokines by human monocytes and $\mathrm{T}$ lymphocytes, this effect of ghrelin is mediated directly through the ghrelin receptors present on immune cells.

The gastric PGE2 level increased in pretreated rats with ghrelin indicating that PGs contribute to the gastroprotective effect of ghrelin. Our results are in agreement with those of Brzozowski et al. (2006) and Sibilia et al. (2008), who proved that COX-1-derived PGs are mainly involved in ghrelin gastroprotection activity. In addition pretreatment with ghrelin in rats subjected to gastric injury was associated with reduction in the lipid peroxidation indicated by the reduction of MDA gastric level together with increased antioxidant activity indicated by GSH and SOD gastric levels these results are going with those of İşeri et al. (2005), who demonstrated that ghrelin administration ameliorates the oxidative injury of the gastric tissue, which appears to involve the inhibition of toxic oxygen metabolite generation, and restoration of tissue GSH which is considered one of the major mechanisms of reducing oxidative stress, either by increasing the synthesis or by inhibiting the depletion of this crucial antioxidant. Also Yada et al. (2006) provided in vitro studies verified that ghrelin increases the mRNA levels of SOD, implicating an antioxidant mechanism of ghrelin. All these data suggest that ghrelin directs the redox reactions toward the reduction state thus reducing the reactivity of oxygen free radicals with other molecules.

Our results have shown that the gastric HO-1 level and its activity increased with pretreatment of ghrelin in INDtreated rats. HO-1 is considered to be a cytoprotective enzyme because each of the products of heme breakdown including $\mathrm{CO}$, iron and biliverdin which is changed into bilirubin plays its own protective role (Ryter et al. 2002). Recent studies have shown that induction of HO-1 has a gastroprotective effect due to the formation of biliverdin and bilirubin with their antioxidant properties, and release of $\mathrm{CO}$, which has anti-inflammatory properties Uc et al. 2012), another possible explanation was reported by Nakao et al. (2008), who reported that a possible explanation for the protective role of HO-1 may lie in the removal of free heme. Free heme has been implicated in the conversion of $\mathrm{H}_{2} \mathrm{O}_{2}$ to more reactive hydroxyl radicals and promoting more severe tissue damage by propagating lipid peroxidation; however, the pretreatment with SnPP, HO-1 blocker, $(30 \mathrm{mg} / \mathrm{kg}$; i.v) resulted in reduction of HO-1 activity without affection of its level as compared with ghrelin-pretreated group, moreover $\mathrm{SnPP}$ ameliorated the gastroprotective effect of ghrelin pretreatment as it resulted in significantly increased U.I with P.I $32.98 \%$ as compared with pretreated group with ghrelin, which was confirmed histopathologically. These findings suggest that the gastroprotective effect of ghrelin against IND-induced gastric injury involves the HO-1 pathway. For our knowledge, this is the first study to show that the decrease in severity of gastric mucosal injury in rats pretreated with ghrelin depends on the HO- 1 enzyme activity.

\section{Conclusion}

In conclusion, the present study revealed that ghrelin pretreatment could improve the outcome of IND-induced gastric injury in rats. This protective effect could be explained on the basis of PG formation, anti-inflammatory and antioxidant effects. We also demonstrate for the first time that HO-1 activation significantly contributes to the gastroprotective effect of ghrelin.

Conflict of interest. The authors declare that they have no conflict of interest.

\section{References}

Abdallah I. Z., Khattab H. A., Heeba G. H. (2011): Gastroprotective effect of Cordia myxa L. fruit extract against indomethacin-induced gastric ulceration in rats. Life Science Journal 8, 433-445

Aburaya M., Tanaka K. I., Hoshino T., Tsutsumi S., Suzuki K., Makise M., Mizushima T. (2006): Heme oxygenase-1 protects gastric mucosal cells against non-steroidal anti-inflammatory drugs. J. Biol. Chem. 281, 33422-33432 https://doi.org/10.1074/jbc.M602074200

Adhikary B., Yadav S. K., Roy K., Bandyopadhyay S. K., Chattopadhyay S. (2011): Black tea and theaflavins assist healing of indomethacin-induced gastric ulceration in mice by antioxidative action. Evid. Based Complement. Alternat. Med. 2011, 546560 https://doi.org/10.1155/2011/546560

Adinortey M. B., Ansah C., Galyuon I., Nyarko A. (2013): In vivo models used for evaluation of potential antigastroduodenal ulcer agents. Ulcers 2013

Alantary A. K., Rezk M. Y., Soliman K. E. A. (2014): Protective effect of ghrelin on paracetamol induced acute hepatotoxicity in rats. J. Physiol. Pathophysiol. 5, 7-14 https://doi.org/10.5897/JPAP2014.0091

Barton S. G. R., Rampton D. S., Winrow V. R., Domizio P., Feakins R. M. (2003): Expression of heat shock protein 32 (hemoxygenase-1) in the normal and inflamed human stomach and colon: an immunohistochemical study. Cell Stress Chaperones 8, 329-334 https://doi.org/10.1379/1466-1268(2003)008<0329:EO$\mathrm{HSPH}>2.0 . \mathrm{CO} ; 2$ 
Bauer M., Bauer I. (2002): Heme oxygenase-1: redox regulation and role in the hepatic response to oxidative stress. Antioxid. Redox Signal. 4, 749-758 https://doi.org/10.1089/152308602760598891

Bhargava K. P., Gupta M. B., Tangri K. K. (1973): Mechanism of ulcerogenic activity of indomethacin and oxyphenbutazone. Eur. J. Pharmacol. 22, 191-195 https://doi.org/10.1016/0014-2999(73)90012-5

Bradley P. P., Christensen R. D., Rothstein G. (1982): Cellular and extracellular myeloperoxidase in pyogenic inflammation. Blood 60, 618-622

Bregonzio C., Armando I., Ando H., Jezova M., Baiardi G., Saavedra J. M. (2003): Anti-inflammatory effects of angiotensin II AT1 receptor antagonism prevent stress-induced gastric injury. Am. J. Physiol. Gastrointest. Liver Physiol. 285, G414-G423 https://doi.org/10.1152/ajpgi.00058.2003

Brzozowski T., Konturek P. C., Sliwowski Z., Pajdo R., Drozdowicz D., Kwiecien S.,Pawlik W. W. (2006): Prostaglandin/cyclooxygenase pathway in ghrelin-induced gastroprotection against ischemia-reperfusion injury. J. Pharmacol. Exp. Therap. 319, $477-487$ https://doi.org/10.1124/jpet.106.105932

Brzozowski T., Tarnawski A., Hollander D., Sekhon S., Krause W. J., Gergely H. (2005): Comparison of prostaglandin and cimetidine in protection of isolated gastric glands against indomethacin injury. J. Physiol. Pharmacol. 56, 75-88

Brzozowski T., Zwirska-Korczala K., Konturek P. C., Konturek S. J., Sliwowski Z., Pawlik M., Pawlik W. W. (2007): Role of circadian rhythm and endogenous melatonin in pathogenesis of acute gastric bleeding erosions induced by stress. J. Physiol. Pharmacol. 58, 53-64

Chen Y. H., Yet S. F., Perrella M. A. (2003): Role of heme oxygenase- 1 in the regulation of blood pressure and cardiac function. Exp. Biol. Med. 228, 447-453

https://doi.org/10.1177/15353702-0322805-03

Cunha F. Q., Boukili M. A., da Motta J. I. B., Vargaftig B. B., Ferreira S. H. (1993): Blockade by fenspiride of endotoxin-induced neutrophil migration in the rat. Eur. J. Pharmacol. 238, 47-52 https://doi.org/10.1016/0014-2999(93)90503-A

Das S. S. M., Vasisht S., Das N., Srivastava L. M., Dubey K. K., Watal G. (2000): Correlation between total antioxidant status and lipid peroxidation in hypercholesterolemia. Current Science (Bangalore) 78, 486-486

de Souza Almeida E. S., Cechinel Filho V., Niero R., Clasen B. K., Balogun S. O., de Oliveira Martins D. T. (2011): Pharmacological mechanisms underlying the anti-ulcer activity of methanol extract and canthin-6-one of Simaba ferruginea A. St-Hil. in animal models. J. Ethnopharmacol. 134, 630-636 https://doi.org/10.1016/j.jep.2011.01.009

Dekanski J. B., Macdonald A., Sacra P., Parke D. V. (1975): Effects of fasting, stress and drugs on gastric glycoprotein synthesis in the rat. Br. J. Pharmacol. 55, 387-392 https://doi.org/10.1111/j.1476-5381.1975.tb06942.x

Dixit V. D., Schaffer E. M., Pyle R. S., Collins G. D., Sakthivel S. K., Palaniappan R., Taub D. D. (2004): Ghrelin inhibits leptinand activation-induced proinflammatory cytokine expression by human monocytes and T cells. J. Clin. Invest. 114, 57-66 https://doi.org/10.1172/JCI200421134
Dhiyaaldeen S. M., Amin Z. A., Darvish P. H., Mustafa I. F., Jamil M. M., Rouhollahi E., Abdulla M. A. (2014): Protective effects of (1-(4-hydroxy-phenyl)-3-m-tolyl-propenone chalcone in indomethacin-induced gastric erosive damage in rats. BMC Vet. Res. 10, 1-14 https://doi.org/10.1186/s12917-014-0303-7

El-Moselhy M. A., Abdel-Hamid N. M., Abdel-Raheim S. R. (2009): Gastroprotective effect of nicorandil in indomethacin and alcoholinduced acute ulcers. Appl. Biochem. Biotechnol. 152, 449-459 https://doi.org/10.1007/s12010-008-8384-z

Fujimoto Y., Uno E., Sakuma S. (2004): Effects of reactive oxygen and nitrogen species on cyclooxygenase-1 and-2 activities. PLEFA 71, 335-340 https://doi.org/10.1016/j.plefa.2004.06.002

Gamal El-Din M. M., Shawky H. M., Seddik H. A., Gamal S. M., Rashed L. A. (2012): Effect of ghrelin on basal gastric acid secretion and ulcer formation in adult male rats and its possible mechanisms of action. Kasr El Aini Medical Journal 18, 49-63

Gaytan F., Barreiro M. L., Chopin L. K., Herington A. C., Morales C., Pinilla L., Tena-Sempere M. (2003): Immunolocalization of ghrelin and its functional receptor, the type 1a growth hormone secretagogue receptor, in the cyclic human ovary. J. Clin. Endocr. Metab. 88, 879-887 https://doi.org/10.1210/jc.2002-021196

Guo J. S., Cho C. H., Wang W. P., Shen X. Z., Cheng C. L., Koo M. W. L. (2003): Expression and activities of three inducible enzymes in the healing of gastric ulcers in rats. World J. Gastroenterol. 9, 1767-1771 https://doi.org/10.3748/wjg.v9.i8.1767

Heeba G. H., Hassan M. K., Amin R. S. (2009): Gastroprotective effect of simvastatin against indomethacin-induced gastric ulcer in rats: role of nitric oxide and prostaglandins. Eur. J. Pharmacol. 607, 188-193 https://doi.org/10.1016/j.ejphar.2009.02.008

Hano J., Bugajski J., Danek L., Wantuch C. (1975): The effect of neuroleptics on the development of gastric ulcers in rats exposed to restraint-cold stress. J. Pharm. Pharmacol. 28, 37-47

Harrison J. L., Miller D. W., Findlay P. A., Adam C. L. (2007): Photoperiod influences the central effects of ghrelin on food intake, GH and LH secretion in sheep. Neuroendocrinology 87, 182-192 https://doi.org/10.1159/000112480

Huang E., Ong W. Y., Go M. L., Garey L. J. (2005): Heme oxygenase-1 activity after excitotoxic injury: Immunohistochemical localization of bilirubin in neurons and astrocytes and deleterious effects of heme oxygenase inhibition on neuronal survival after kainate treatment. J. Neurosci. Res. 80, 268-278 https://doi.org/10.1002/jnr.20444

Íşeri S. Ö., Şener G., Yüksel M., Contuk G., Çetinel Ş., Gedik N., Yeğen B. Ç. (2005): Ghrelin against alendronate-induced gastric damage in rats. J. Endocrinol. 187, 399-406 https://doi.org/10.1677/joe.1.06432

Jazwa A., Cuadrado A. (2010): Targeting heme oxygenase-1 for neuroprotection and neuroinflammation in neurodegenerative diseases. Curr. Drug Targets 11, 1517-1531 https://doi.org/10.2174/1389450111009011517

Khalefa A. A., Abd-Alaleem D. I., Attiaa K. I. (2010): The protective effects of ghrelin and leptin against stress-induced gastric ulcer in rats. Arab. J. Gastroenterology 11, 74-78 
https://doi.org/10.1016/j.ajg.2010.04.005

Kim J. H., Kim B. W., Kwon H. J., Nam S. W. (2011): Curative effect of selenium against indomethacin-induced gastric ulcers in rats. J. Microbiol. Biotechnol. 21, 400-404

Kojima M., Kangawa K. (2005): Ghrelin: structure and function. Physiol. Rev. 85, 495-522

https://doi.org/10.1152/physrev.00012.2004

Konturek P. C., Brzozowski T., Pajdo R., Nikiforuk A., Kwiecien S., Harsch I., Konturek S. J. (2004): Ghrelin - a new gastroprotective factor. J. Physiol. Pharmacol. 55, 325-336

Laine L., Takeuchi K., Tarnawski A. (2008): Gastric mucosal defense and cytoprotection: bench to bedside. Gastroenterol. 135, 41-60

https://doi.org/10.1053/j.gastro.2008.05.030

Motterlini R., Foresti R., Intaglietta M., Winslow R. M. (1996): NO-mediated activation of heme oxygenase: endogenous cytoprotection against oxidative stress to endothelium. Am. J. Physiol. Heart Circ. Physiol. 270, H107-H114

Nakao A., Kaczorowski D. J., Sugimoto R., Billiar T. R., McCurry K. R. (2008): Serial review application of heme oxygenase-1, carbon monoxide and biliverdin for the prevention of intestinal ischemia/reperfusion injury. J. Clin. Biochem. Nutr. 42, 78-88 https://doi.org/10.3164/jcbn.2008013

Natale G., Lazzeri G., Lubrano V., Colucci R., Vassalle C., Fornai M., Del Tacca M. (2004): Mechanisms of gastroprotection by lansoprazole pretreatment against experimentally induced injury in rats: role of mucosal oxidative damage and sulfhydryl compounds. Toxicol. Appl. Pharmacol. 195, 62-72

https://doi.org/10.1016/j.taap.2003.10.006

Ohkawa H., Ohishi N., Yagi K. (1979): Assay for lipid peroxides in animal tissues by thiobarbituric acid reaction. Anal. Biochem. 95, 351-358 https://doi.org/10.1016/0003-2697(79)90738-3

Polat B., Albayrak Y., Suleyman B., Dursun H., Odabasoglu F., Yigiter M., Suleyman H. (2011): Antiulcerative effect of dexmedetomidine on indomethacin-induced gastric ulcer in rats. Pharmacol. Rep. 63, 518-526 https://doi.org/10.1016/S1734-1140(11)70518-7

Prasad S. V., Srinivas A., Ambareesh K., Nayak B. B., Shinde B. B., Ambadas B. (2012): Protective role of oxitard in drug induced ulcers in rats. Int. J. Biol. Med. Res. 3, 1948-1951

Ryter S. W., Otterbein L. E., Morse D., Choi A. M. (2002): Heme oxygenase/carbon monoxide signaling pathways: regulation and functional significance. Mol. Cell. Biochem. 234, 249-263 https://doi.org/10.1023/A:1015957026924

Sabina E. P., Rasool M. (2007): Therapeutic efficacy of Indian ayurvedic herbal formulation triphala on lipid peroxidation, antioxidant status and inflammatory mediator TNF- $\alpha$ in adjuvant-induced arthritic mice. Int. J. Biol. Chem. 1, 149-155 https://doi.org/10.3923/ijbc.2007.149.155

Sedlak J., Lindsay R. H. (1968): Estimation of total, protein-bound, and nonprotein sulfhydryl groups in tissue with Ellman's reagent. Anal. Biochem. 25, 192-205 https://doi.org/10.1016/0003-2697(68)90092-4

Shibahara S. (2003): The heme oxygenase dilemma in cellular homeostasis: new insights for the feedback regulation of heme catabolism. Tohoku J. Exp. Med. 200, 167-186 https://doi.org/10.1620/tjem.200.167
Sibilia V., Pagani F., Rindi G., Lattuada N., Rapetti D., De Luca V., Netti C. (2008): Central ghrelin gastroprotection involves nitric oxide/prostaglandin cross-talk. Br. J. Pharmaco. 154, 688-697 https://doi.org/10.1038/bjp.2008.120

Sibilia V., Rindi G., Pagani F., Rapetti D., Locatelli V., Torsello A., Netti C. (2003): Ghrelin protects against ethanol-induced gastric ulcers in rats: studies on the mechanisms of action. Endocrinology 144, 353-359 https://doi.org/10.1210/en.2002-220756

Song H. J., Shin C. Y., Oh T. Y., Sohn U. D. (2008): The protective effect of eupatilin on indomethacin-induced cell damage in cultured feline ileal smooth muscle cells: involvement of HO-1 and ERK. J. Ethnopharmacol. 118, 94-101 https://doi.org/10.1016/j.jep.2008.03.010

Suleyman H., Cadirci E., Albayrak A., Polat B., Halici Z., Koc F., Bayir Y. (2009): Comparative study on the gastroprotective potential of some antidepressants in indomethacin-induced ulcer in rats. Chem. Biol. Interact. 180, 318-324 https://doi.org/10.1016/j.cbi.2009.03.002

Suzuki H., Masaoka T., Nomoto Y., Hosoda H., Mori M., Nishizawa T., Hibi T. (2006): Increased levels of plasma ghrelin in peptic ulcer disease. Aliment. Pharmacol. Ther. 24, 120-126 https://doi.org/10.1111/j.1365-2036.2006.00034.x

Takeuchi K., Tanaka A., Nukui K., Kojo A., Gyenge M., Amagase K. (2011): Aggravation by paroxetine, a selective serotonin reuptake inhibitor, of antral lesions generated by nonsteroidal anti-inflammatory drugs in rats. J. Pharmacol. Exp. Therap. 338, 850-859

https://doi.org/10.1124/jpet.111.183293

Tulassay Z., Herszényi L. (2010): Gastric mucosal defense and cytoprotection. Best Pract. Res. Clin. Gastroenterol. 24, 99-108 https://doi.org/10.1016/j.bpg.2010.02.006

Uc A., Zhu X., Wagner B. A., Buettner G. R., Berg D. J. (2012): Heme oxygenase- 1 is protective against nonsteroidal antiinflammatory drug-induced gastric ulcers. J. Pediatr. Gastroenterol. Nutr. 54, 471-476 https://doi.org/10.1097/MPG.0b013e3182334fdf

Wagener F. A., da Silva J. L., Farley T., de Witte T., Kappas A., Abraham N. G. (1999): Differential effects of heme oxygenase isoforms on heme mediation of endothelial intracellular adhesion molecule 1 expression. J. Pharmacol. Exp. Therap. 291, 416-423

Wagener F. A., Eggert A., Boerman O. C., Oyen W. J., Verhofstad A., Abraham N. G., Figdor C. G. (2001): Heme is a potent inducer of inflammation in mice and is counteracted by heme oxygenase. Blood 98, 1802-1811 https://doi.org/10.1182/blood.V98.6.1802

Yada T., Kaiya H., Mutoh K., Azuma T., Hyodo S., Kangawa K. (2006): Ghrelin stimulates phagocytosis and superoxide production in fish leukocytes. J. Endocrinol. 189, 57-65 https://doi.org/10.1677/joe.1.06187

Yoda Y., Amagase K., Kato S., Tokioka S., Murano M., Kakimoto K., Higuchi K. (2010): Prevention by lansoprazole, a proton pump inhibitor, of indomethacin-induced small intestinal ulceration in rats through induction of heme oxygenase-1. J. Physiol. Pharmacol. 61, 287-294

Received: October 1, 2016

Final version accepted: December 5, 2016 